\title{
Induction of Labour at Term: Comparison of Prostaglandin E2 with Foley Catheter
}

Mehreen Yousaf Rana, Habiba Sharaf Ali, Ome Kulsoom, Rehana Yasmeen, Rabel Gul

Department of Obstetrics and Gynaecology, Dr. Ziauddin Hospital, Karachi, Pakistan.

\section{BSTRACT}

Background: Induction of labour (IOL) or cervical ripening of an unfavourable cervix can be achieved by both pharmacological and surgical methods. When the cervix is unripe, Foley catheters and prostaglandins method of $\mathrm{IOL}$ is used. In this study, we aimed to compare the success rate and cost-effectiveness of vaginal prostaglandin E2 pessary with Foley catheter.

Methods: This quasi-experimental study was conducted at the Gynaecological department of Ziauddin hospital from June-December 2019. A total of $n=256$ women at term were selected according to inclusion criteria. Group 1 was induced with Foley catheter and group 2 with Prostaglandins E2 vaginal pessary. The success rate to achieve delivery, the time interval between induction, delivery and the cost were recorded and compared between the two methods. Student's t-test (continuous variables) and Chi-square (categories) were used for statistical analysis and $p$-value $<0.05$ was considered statistically significant.

Results: The mean age of the females was $27.15 \pm 5.5$ years. The mean induction to the delivery time interval for PGE2 (group 2) was $15.77 \pm 7.37$ hours and Foley catheter (group 1) $17.31 \pm 7.19$ hours $(p=0.02)$. The study did not find any statistically significant difference between the two methods of labour induction ( $p>0.05)$. It was found that overall, 198 (77.3\%) women delivered by spontaneous vaginal deliveries and $58(22.7 \%)$ by lower Caesarean section $(p=0.02,0.04)$. However, the total cost of prostaglandins(Rs.1500/-) was higher than the cost of Foley catheter(Rs. 256/-) $(p=0.00)$.

Conclusion: Foley catheter to induce labour in an unfavourable cervix is an effective, safe, and inexpensive method of labour induction.

Keywords: Foley Catheter; Prostaglandin E2; Induction of Labour; Cost.

\section{Corresponding Author:}

\section{Dr. Ome Kulsoom}

Department of Obstetrics and Gynaecology,

Dr. Ziauddin Hospital,

Karachi, Pakistan.

Email: drkulsoomsarfaraz@gmail.com

https://doi.org/10.36283/PJMD11-1/009

How to cite: Rana MY, Ali HS, Kulsoom O, Yasmeen R, Gul R. Induction of Labour at Term: Comparison of Prostaglandin E2 with Foley Catheter. 2022;1 1 (1): 50-55. doi: 10.36283/PJMD1 1-1/009

\section{INTRODUCTION}

Around $20 \%-25 \%$ of pregnancies end up in induction of labour from which the same percentage of women end up in failed induction and Caesarean section ${ }^{1,2}$. Cervical condition determines the success of labour induction efforts, such that when the cervix is ripe and the bishop score (Bishop Score is applied to predict the likelihood of successful 
vaginal delivery by taking account of the dilatation of cervix (0->5cm) \% of effacement (0-3), station (0-3), position (0-2) and consistency (0-2) is good artificial rupture of membranes can be done) ${ }^{3}$. When the cervix is unfavourable and the bishop score is not good, we used different methods to ripe the cervix so it starts to dilate. Cervical ripening refers to the softening of the cervix that typically begins before the onset of labour contractions and is necessary for cervical dilation and the passage of the fetus ${ }^{4}$.

Induction of labour (IOL) or cervical ripening of an unfavourable cervix can be achieved by both pharmacological and surgical methods. Some of the pharmacological drugs used for induction of labour are Prostaglandin E1, E2, and F2 alpha. While the mechanical method adopted is the passage of a Foley catheter in the internal os of the cervix. Catheter applies pressure on the cervix and indirectly increases localized secretion of prostaglandins and/or oxytocin. The prostaglandins bring about biological changes in the cervix and initiate uterine contraction ${ }^{5,6}$.

Indications include both maternal and fetal conditions. Some of the common indications are post-maturity, preeclampsia, diabetes mellitus, intrauterine growth retardation, oligohydramnios, and premature rupture of membrane etc ${ }^{7}$. Some of the complications of induction of labour are failure of induction of labour which ends up in Caesarean section in around $20 \%$ and hyper-stimulation of the uterus resulting in uterine rupture and fetal distress ${ }^{2,8}$. The WHO recommended labour induction with the use of Foley catheter as a first-line option is being adopted worldwide?.

The current study did a comparison of two common methods of labour induction i.e. prostaglandin E2 pessary and Foley catheter in the context of the unfavourable condition of the cervix. The interval between induction and delivery was also compared. Since induction is carried out for cervical ripening in many cases which requires a substantial amount of healthcare efforts and resources. Few studies have evaluated the cost-effectiveness between the two methods in which Prostaglandin E2 pessary is expensive compared to Foley catheter: on average Rs 2000 versus Rs. 260 per induction respectively ${ }^{10,11}$. Therefore, we are a developing country and affordability is a major concern for most of our population. The current study was done to compare success rates and the cost-effectiveness of Prostaglandin E2 versus Foley catheter for induction of labour in women at term pregnancy.

\section{METHODS}

The study was a quasi-experimental trial and included 256 women requited to the Department of
Obstetrics and Gynaecology of Ziauddin Hospital for six months from June 2019-December 2019. The study was conducted after approval from the Ethics Review Committee of the Institute. The women with term pregnancy requiring induction of labour for any indication, parity $\leq 4$, singleton fetus with vertex presentation and Bishop's score $\leq 5$ was included. Mothers with multiple pregnancies, placenta previa previous, previously caesarean section, non-vertex presentation at birth, with ruptured membrane and gestational age less than 37 completed weeks of gestation were excluded from the study.

After getting informed written or verbal consent, the women eligible as per selection criteria were included for induction of labour. A sample was divided into two groups (viz; group 1 and group 2) on a subsequent basis (i.e., alternately). There was one to one ratio of women recruited in each group. Foley catheter was used for induction of labour among women in group 1 while women in group 2 were induced with Prostaglandin E2 pessaries (PGE2). Women were counselled about the procedure in detail before the data collection while taking written consent for emergency caesarean section. A detailed history was noted regarding women's age, parity, and gestational age. A baseline CTG was performed and an abdominal and pelvic examination was performed. Bishop scoring was done and uterine contractions were assessed.

Women assigned to Group 1 were treated with a Foley catheter. After lithotomy position of women, the cervix was exposed through introducing a sterile Cusco speculum. The cervix was cleansed with an antiseptic solution and a 22-24 G Foley catheter was put in through the external cervical os with the help of a sponge holding forceps. Fifty $\mathrm{ml}$ of distal water was injected to inflate the balloon. The Foley catheter was stick to the women's thigh to maintain traction. Prophylactic antibiotics were administered and continued for 24 hours. The catheter was deflated after 24 hours if it did not fall out by itself. If the Foley catheter falls out within 24 hours, the amniotic membrane was ruptured and if needed, oxytocin infusion is started for labour augmentation.

Women in Group 2 were given 3mg PGE2 pessary (Prostin Upjohn). With a maximum limit of using three times (repeated only after six hours), the pessary was placed in the posterior vaginal fornix. The pessary was administered by the on-call doctor and the medication was stopped if the woman was found to be in the active phase of labour that is when the cervix is $\geq 3 \mathrm{~cm}$ dilated and uterine contractions are 3 in 10 minutes. If labour is not initiated after three doses of PGE2, amniotic membranes were ruptured artificially and oxytocin infusion was administered. 
Fetal monitoring and the onset of labour were observed at half-hour intervals regularly while the progress of labour was assessed at an interval of four hours. Failed induction was categorized as cervix unfavourable for an ARM after three applications of PGE2 pessary or after spontaneous expulsion of Foley catheter or 24 hours have passed since insertion. The data analysis was performed through Statistical Package for Social Sciences (SPSS) version 20. To calculate cost-effectiveness both costs of Foley catheter and PGE2 used were compared. Statistical tests applied included students' t-test (continuous variables) and Chi-square (categories) with a p-value < 0.05 considered statistically significant.

\section{RESULTS}

There were 256 women in this study, 128 women in each group. The minimum age of participant was 17 years, the maximum age was 37 years, and the mean age was $27.15 \pm 5.5$ years. The other demographic characteristics of the women are also shown in Table 1. Of the 128 women in group 2 receiving $P G E 2 ; 48(37.5 \%)$ women required only one pessary while $80(62.5 \%)$ women were administered two pessaries. Regardless of the number of PGE2 doses required, $27(21.09 \%)$ women did not need syntocinon infusion, 10(7.81\%) women had spontaneous rupture of membranes while 97(75.78\%) needed artificial rupture of the membranes.

Table 1: Age groups and gestational week, regarding Foley Catheter and PGE2.

\begin{tabular}{|c|c|c|c|c|c|c|}
\hline $\begin{array}{l}\text { Age Groups } \\
\text { (years) n (\%) }\end{array}$ & $17-23$ & $24-30$ & $31-37$ & $\begin{array}{l}\text { Foley Cathete } \\
\text { Mean } \pm \text { SD }\end{array}$ & $\begin{array}{l}\text { PGE2 } \\
\text { Mean士 SD }\end{array}$ & $p$-Value \\
\hline$n=256$ & $\begin{array}{c}86 \\
(33.60 \%)\end{array}$ & $\begin{array}{c}87 \\
(34 \%)\end{array}$ & $\begin{array}{c}83 \\
(32.40 \%)\end{array}$ & $27.10 \pm 5.644$ & $27.07 \pm 5.628$ & $>0.05$ \\
\hline $\begin{array}{l}\text { Gestational age } \\
\text { in weeks n (\%) }\end{array}$ & $37-38$ & $39-40$ & Above 40 & $\begin{array}{c}\text { Foley Catheter } \\
\text { Mean } \pm \text { SD }\end{array}$ & $\begin{array}{l}\text { PGE2 } \\
\text { Mean } \pm \text { SD }\end{array}$ & $p$-Value \\
\hline$n=256$ & $\begin{array}{c}86 \\
133.60 \%\end{array}$ & $\begin{array}{c}119 \\
146.50 \%\end{array}$ & $\begin{array}{c}51 \\
(19.50 \%)\end{array}$ & $39.27 \pm 1.433$ & $39.20 \pm 1.324$ & $>0.05$ \\
\hline
\end{tabular}

PGE2 = Prostaglandin E2 (PGE2).

In Foley catheter group, 5(3.9\%) women had spontaneous rupture of the membranes and $123(96.1 \%)$ required artificial rupture of the membranes, $12(9.37 \%)$ women did not require syntocinon infusion. The mean induction to the delivery time interval for PGE2 was $15.77 \pm 7.37$ hours and Foley catheter $17.31 \pm 7.19$ hours (Table 2). This table also shows the duration of labour in primigravida and multiparas in each group.

Table 2: Induction to delivery time interval.

\begin{tabular}{|l|c|c|c|}
\hline Time Interval & Foley Catheter & Prostaglandin E2 (PGE2) & p-Value \\
\hline All women & $17.3 \pm 7.19$ & $15.77 \pm 7.37$ & 0.02 \\
\hline Primipara & $21 \pm 8.0$ & $18 \pm 9.0$ & 0.03 \\
\hline Multipara & $15 \pm 6.0$ & $14 \pm 5.0$ & 0.02 \\
\hline LSCS & $23.6 \pm 12.0$ & $16.87 \pm 9.0$ & 0.04 \\
\hline SVD & $16.27 \pm 5.0$ & $15.53 \pm 7.0$ & 0.02 \\
\hline
\end{tabular}

LSCS=Lower segment caesarean section, SVD =spontaneous vaginal delivery.

In the analysis of outcome at 30 hours, it was found that overall, 198(77.3\%) women delivered by spontaneous vaginal deliveries and $58(22.7 \%)$ by lower Caesarean section. The mode of delivery in the two groups did not show a significant difference,
$102(79.7 \%)$ women in the Foley catheter group and $96(75 \%)$ in the PGE2 group delivered by spontaneous vaginal delivery, which can be seen in the graphical representation of the collected data $(p$-value $=0.370 ;$ Figure 1$)$. 


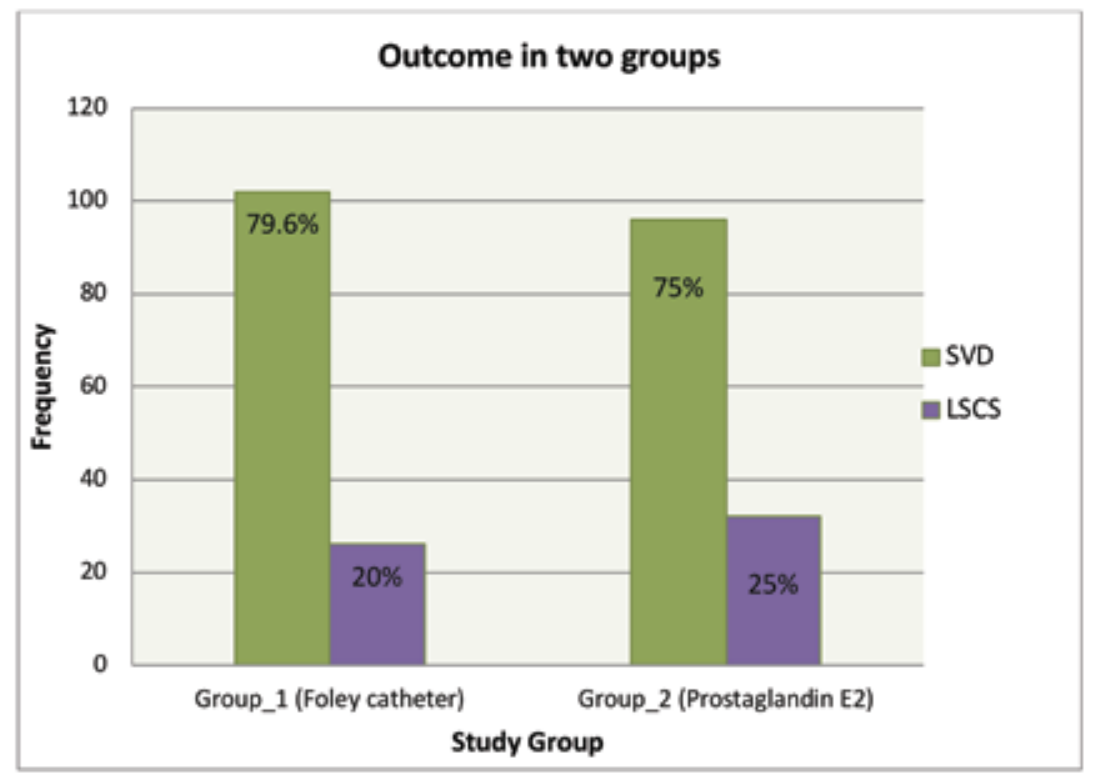

Figure 1: Comparison of the outcome in two groups.

For $48(37.5 \%)$ women only one pessary was used while for the other $80(62.5 \%)$ women two pessaries were used. Finally, a comparison of the cost of induction in the two groups revealed that the mean cost per prostaglandins vaginal pessary was Rs.1500/-. The maximum cost was Rs 3000/- per patient. In addition, the prostaglandin requires storage and transport at a temperature of $2-5^{\circ} \mathrm{C}$ to maintain its potency. On the other hand, the total mean cost of Foley catheter was Rupees 256/resulting in major cost savings. Mean cost of treatment in both groups were also compared with Foley Catheter (256.11 \pm 50$)$ and Prostaglandin E2 (PGE2) $(1500 \pm 500)$ respectively had a calculated $p$-value of 0.001 .

\section{DISCUSSION}

About $15 \%$ of labours are induced for various reasons ${ }^{5-7}$. There is a rise in the rate of induction during the last few years ${ }^{12}$. The induction rate in Pakistan has been found to vary from 20 to $24 \%{ }^{13}$. For induction to be successful, the cervix must be ripened before the process starts. There are various methods used for cervical ripening during the induction of labour. It is still under debate which of these methods of treatment is best and idea ${ }^{8,9-11}$. In this study, we compared two commonly used methods i.e., Foley catheter and PGE2 for cervical ripening ${ }^{13}$.

In the current study, no difference was found in the success rate and mode of delivery of the two study groups. Caesarean section rate was almost similar in both groups. These results are consistent with the previous studies but differ from those, which had established higher efficacy of Foley catheter expressed as a lower caesarean section rate in comparison to other methods ${ }^{14-16}$. In this study, both groups were compared regarding "induction to delivery interval". It was found with statistical significance ( $p$-value 0.02) that duration was lengthier in the Foley catheter group than in the PGE2 groups, whether the woman was primipara or multipara and whether delivered through LSCS or SVD ( $p$-valves $=0.03,0.02,0.04$ and 0.02 respectively). Regarding the need for oxytocin for augmentation, more women received oxytocin infusion in group 1 in comparison to Group 2.

A retrospective analysis done by Manly and co-workers comparing Foley catheter and PGE gel for cervical ripening in multiparous women concluded that the success rates of both methods are the same, however; the time interval from induction to delivery was more in the PGE2 group compared to Foley catheter group ${ }^{17}$. Efficacy and safety of Foley catheter balloon compared with the locally applied prostaglandins for cervical ripening followed by the labour induction among term pregnancies was analyzed systematically in a study. This study using the data of 27 randomized control trials concluded that there was no significant difference between the two methods in caesarean deliveries. The prostaglandins were associated with the significantly increased risk of hyperstimulation while women induced with Foley catheter required significantly higher oxytocin induction/ augmentation during labor ${ }^{18}$.

Another meta-analysis including 1191 women compared intracervical Foley with PGEl found similar success rates in both groups, no difference in the Caesarean section rate and side effects such as hyperstimulation and post-partum haemorrhage between the two groups ${ }^{19}$. However; in contrast to 
this, a prospective multicenter randomized trial published in 2015 comparing intra-cervical Foley catheter with prostaglandins found a significantly higher failure rate of induction of labour in Foley catheter group compared with the prostaglandin group. They also found a higher rate of oxytocin infusion in Foley catheter group but their rate of caesarean section was similar in both groups ${ }^{20}$. The PROBAAT trial including 824 women compared Foley catheter with PGE2 gel. These results showed a much higher incidence of the caesarean section when induced with Foley catheter than using prostaglandins. Nevertheless, the study lacked statistical significance ${ }^{21}$.

Wang et al. in a clinical trial concluded that Foley catheter is more effective for pre-induction ripening of unfavourable cervix in comparison with PGE2 gel $^{21}$. In a recent meta-analysis published in BJOG, the double-balloon catheter was found to be safer and cost-effective for cervical ripening and labour induction than the PGE. However, both methods were equally effective in bringing successful vaginal delivery 22 . A study by Kanada and Jain comparing these methods found no difference in the efficacy and success rate 23 . Similar findings as that of Kanada and Jain are reported by Laddad et al. where they found that for pre-induction cervical ripening both the Foley's catheter and the PGE2 gel are equally effective ${ }^{24}$. Likewise, an equal efficacy and safety of a double-balloon catheter and dinoprostone were described in a recent trial conducted by Liu et al., ${ }^{25}$ having similar results as shown in this study.

It was also found that Foley catheter was at least as effective as vaginal prostaglandin PGE2 for pre-induction cervical ripening. It was safe and accepted by most women. Cost-wise also it was much cheaper than Prostaglandins. PGE2 is almost six times more expansive than the Foleys while it also requires cold temperature for storage. Our healthcare system and poor population cannot afford such a costly method as a routine use-leaving apart some contraindications. In third world countries, it is a preferred method of choice than prostaglandins. However, few variables are considered in this study. There is a need to include more parameters such as neonatal outcomes and side effects and complications of inducing agents.

\section{CONCLUSION}

Foley balloon catheter was found an effective method for cervical ripening. It is simple, safe, reversible, and low cost and it lacks systemic or severe side effects. Though, prostaglandin is effective but is an expensive method. Its high cost, storage, and transport at lower temperatures to maintain its potency, makes it less favourable compared to Foley catheter.

\section{ACKNOWLEDGEMENTS}

The authors acknowledged Ziauddin Hospital for facilitating the research study.

\section{CONFLICT OF INTEREST}

The authors declared no conflict of interest.

\section{ETHICS APPROVAL}

The ethics review committee of the institute approved the study.

\section{PATIENT CONSENT}

Written and verbal consent were obtained from the participants of the study.

\section{AUTHORS' CONTRIBUTION}

All authors equally contributed to the study.

\section{REFERENCES}

1. Kordi M, Meybodi FA, Tara F, Fakari FR, Nemati M, Shakeri M. Effect of Dates in Late Pregnancy on the Duration of Labour in Nulliparous Women. Iran J Nurs Midwifery Res. 2017;22(5):383-383. doi: 10.4103/ijnmr.IJNMR_213_15

2. World Health Organization: WHO recommendations for induction of labour, Department of reproductive health and research. Geneva, Switzerland: World Health Organization; $2011: 32$.

3. Laughon SK, Zhang J, Troendle J, Sun L, Reddy UM. Using a simplified Bishop score to predict vaginal delivery. Obstet Gynecol. 2011;117(4):805-811. doi: 10.1097/AOG.0b013e3182114ad2

4. Alfirevic Z, Kelly AJ, Dowswell T. Intravenous oxytocin alone for cervical ripening and induction of labour. Cochrane Database Syst Rev. 2009; 4(CD003246):1-75. doi: 10.1002/14651858.CD003246 .pub2

5. Smith V, Gallagher L, Carroll M, Hannon K, Begley C. Antenatal and intrapartum interventions for reducing caesarean section, promoting vaginal birth, and reducing fear of childbirth: An overview of systematic reviews. PLoS One. 2019;14(10):1-17. doi: 10.1371/journal.pone.02243135-

6. Alfirevic Z, Keeney E, Dowswell T, Welton NJ, Medley N, Dias S, et al. Which method is best for the induction of labour? A systematic review, network meta-analysis and cost-effectiveness analysis. Health Technol Assess. 2016;20(65):1-583. doi: 10.3310/hta20650

7. Lawani OL, Onyebuchi AK, lyoke CA, Okafo CN, Ajah LO. Obstetric outcome and significance of labour induction in a health resource poor setting. Obstetrics and gynaecology international. 2014;2014:1-5. doi: 10.1155/2014/419621

8. Vlemminx MW, de LaU H, Oei SG. Tocogram characteristics of uterine rupture: a systematic review. Arch Gynecol Obstet. 2017;295(1):17-26. doi: 10.1007/s00404-016-4214-7

9. Khamaiseh K, Al-Ma'ani W, Abdalla I. Prostaglandin E2 versus Foley catheter balloon for induction of labour at term: A randomized controlled study. J 
Royal Med Serv. 2012;19(4):42-47.

10. Van Baaren GJ, Jozwiak M, Opmeer BC, Oude Rengerink K, Benthem M, Dijksterhuis MG, et al. Cost-effectiveness of induction of labour at term with a Foley catheter compared to vaginal prostaglandin $E_{2}$ gel (PROBAAT trial). Int J Obstet Gynaecol. 2013;120(8):987-995. doi: 10.1111/1471-0528.12221

11. Arif N, Mushtaq M. Foley Catheter insertion versus prostaglandin E2 vaginal pessary. Pak Armed Forces Med J. 2010;60(1):104-108.

12. Ziyauddin F, Hakim S, Beriwal S. The trans-cervical foley catheter versus the vaginal prostaglandin E2 gel in the induction of labour in a previous one caesarean section - A clinical study. J Clin Diagn Res. 2013;7(1): 140-143. doi: 10.7860/JCDR/2012/ 5003.2689

13. Mazhar SB, Jabeen K. Outcome of mechanical mode of induction in failed primary labor induction. J Coll Physicians Surg Pak. 2005;15(10):616-619.

14. Niromanesh S, Mosavi-Jarrahi A, Samkhaniani F. Intracervical Foley catheter balloon vs. prostaglandin in preinduction cervical ripening. Int J Gynecol Obstet. 2003;81(1):23-27. doi: 10.1016/S0020-7292 (02)00392-2

15. Cromi A, Ghezzi F, Tomera S, Uccella S, Lischetti $B$, Bolis PF. Cervical ripening with the Foley catheter. Int J Gynecol Obstet. 2007;97:105-109. doi: 10.1016/j.ijgo.2006.10.014

16. Eser A, Ozkaya E, Abide CY, Eser T, Eser GY, Abike F, et al. Transcervical Foley balloon catheter and vaginal prostaglandin E2 insert combination vs. vaginal prostaglandin E2 insert only for induction of labour at term: a randomized clinical trial. Arch Gynecol Obstet. 2019;299(2):451-457. doi: 10.1007/s00404018-4998-8

17. Manly E, Hiersch L, Moloney A, Berndl A, Mei-Dan E, Zaltz A, et al. Comparing Foley Catheter to Prostaglandins for Cervical Ripening in Multiparous Women. J Obstet Gynaecol Can. 2020;42(7):853-860. doi: 10.1016/j.jogc.2019.11.001

18. Vaknin Z, Kurzweil Y, Sherman D. Foley catheter balloon vs locally applied prostaglandins for cervi- cal ripening and labour induction: A systematic review and meta-analysis. Am J Obstet Gynecol. 2010;203(5):418-429. doi: 10.1016/j.ajog.2010.04.038 19. Zhu L, Zhang C, Cao F, Liu Q, Gu X, XU J, et al. Intracervical Foley catheter balloon versus dinoprostone insert for induction cervical ripening: A systematic review and meta-analysis of randomized controlled trials. Medicine (Baltimore). 2018;97(48):1-10. doi: 10.1097/MD.0000000000013251

20. Løkkegaard E, Lundstrøm M, Kjaer MM, Christensen IJ, Pedersen HB, Nyholm H. Prospective multi-centre randomised trial comparing induction of labour with a double-balloon catheter versus dinoprostone. J Obstet Gynaecol. 2015;35(8):797-802. doi: 10.3109/01 443615.2015.1011101

21. Wang H, Hong S, Liu Y, Duan Y, Yin H. Controlled-release dinoprostone insert versus Foley catheter for labour induction: a meta-analysis. J Matern Fetal Med. 2016;29(14):2382-2388. Doi: 10.3109/14767058. 2015.1086331

22. Du YM, Zhu LY, Cui LN, Jin BH, Ou JL. Double-balloon catheter versus prostaglandin E2 for cervical ripening and labour induction: a systematic review and meta-analysis of randomised controlled trials. Int J Obstet Gynaecol. 2017;124(6):891-899. doi: 10.1111/1471-0528.14554

23. Kanada AR, Jain M. A comparative study of intra-cervical Foley's catheter and PGE2 gel for induction of labour at term. Int J Reprod Contracept Obstet Gynecol. 2019;8(9):3689-3693. doi: 10.18203/2320-1770.jijrcog20193799

24. Laddad MM, Kshirsagar NS, Karale AV. A prospective randomized comparative study of intra-cervical Foley's catheter insertion versus PGE2 gel for pre-induction cervical ripening. Int J Reprod Contracept Obstet Gynecol. 2013;2(2):217-220.

25. Liu YR, Pu CX, Wang XY, Wang XY. Double-balloon catheter versus dinoprostone insert for labour induction: a meta-analysis. Arch Gynecol Obstet. 2019;299(1):7-12. doi: 10.1007/s00404-018-4929-8. 